\section{The Soaring of Birds}

IN the discussion about the soaring of birds which has lately been carried on in NATURE, I do not remember to have observed that any one quoted from Mr. Darwin's account of the condor. He says ("A Naturalist's Voyage Round the World," chap. ix. p. 186) :- "When the condors are wheeling in a flock round and round any spot their flight is beautiful. Except when rising from the ground, I do not recollect ever having seen one of these birds flap its wings. Near Lima, I watched several for nearly half an hour, without once taking off my eyes: they moved in large curves, sweeping in circles, descending and ascending without giving a single flap. . . The head and neck were moved frequently, and apparently with force; and the extended wings seemed to form the fulcrum on which the movements of the neck, body, and tail acted. If the bird wished to descend, the wings were for a moment collapsed; and when again expanded with an altered irclination, the momentum gained by the rapid descent seemed to urge the bird upwards with the even and steady movement of a paper kite. In the case of any bird soaring, its motion must be sufficiently rapid, so that the action of the inclined surface of its body on the atmosphere may counterbalance its gravity."

Cambridge, May I 7 JAMES CURRIE

\section{Intelligence in a $\mathrm{Dog}$}

Some time since a friend of mine, Mr. J. W. Schaub, a mechanical engineer at the Edgmore Ironworks of Wilmington, Del., informed me of an exceedingly interesting case of intelligence in a black and tan terrier belonging to him. The old mother dog and her playful family entered his bedroom while he was dressing, and one of the pups snatched his stocking as he was in the act of putting it on, running out of the room with it. The mother at once followed the young offender, took the stocking from him, and returned it to the master. $\mathrm{Mr}$. Schaub said that her conduct gave evidence of displeasure at the action of the pup, and she impressed him with the idea that she felt in some way responsible for the conduct of her young. Being greatly interested in the matter, Mr. Schaub contrived $t$ s have the offence committed on many successive mornings, the same performance being repeated each time.

$$
\text { St. Louis, U.S., April } 24
$$

FRANCIS E. NiPHER

\section{Mid-height of Sea Waves}

CAN any of your readers furnish me with the formula, or other means, for finding the difference between the mid-height of a sea-wave and the sea-level?

W. PARFITT

\section{A CURIOUS SURVIVAL}

TH $\mathrm{HE}$ thirteenth Annual Report of the Deputy Master of the Mint, just issued, contains some interesting information showing how persistently an ancient system of computing the value of bullion has survived in this country. The facts are fully set forth in an appendix to the Report by Prof. Chandler Roberts, who has recently and successfully advocated the adoption of the decimal system in the bullion transactions of the Mint. In order to make the matter clear, it may be well to state that the Troy pound, still used in this country for weighing the precious metals, is believed to have been derived from the Roman weight of $5759^{\circ} 2$ grains, the $125^{\text {th }}$ part of the large Alexandrian talent; this weight, like the Troy pound, having been divided by the Romans into I2 ounces. The earliest statute of this kingdom in which the Troy weight is named is the 2 Henry V. st. 2 , c. 4 , but the Troy weight is universally allowed to have been in general use from the time of King Edward I. The most ancient system of weights in this kingdom was the Moneyer's pound or the money pound of the AngloSaxons, which was continued in use for some centuries after the Conquest, being then known as the "Tower pound," or sometimes the Goldsmith's pound. It contained 12 ounces of 450 grains each, or 5400 grains, and this weight of silver was a pound sterling. The Tower pound was abolished in 1527 by a statute of Henry VIII., which first established Troy weight as the only legal weight for gold and silver, and from this time to the present our system of coinage has been based on the Troy weight, the Troy pound containing 5760 grains. ${ }^{1}$

The bullion transactions of the Mint have hitherto been based on an Assayer's weight termed the "carat pound," the final division of which corresponds with the number of grains in the Troy pound, and side by side with this system a curious method of expressing the 'standard' or composition of ingots or coins of gold and silver has been retained until the present year. For instance, the ordinary conception of the composition of a sovereign would be that it is an alloy or mixture of the two metals gold and copper in definite proportions, and the most simple way of expressing its contents would be to describe them as consisting of 91.66 per cent. of gold and 8.34 per cent. of copper. An assayer or bullion dealer, on the other hand, using the old system, would simply consider the composition of the coin to be gold of 'standard fineness,' that is to say, containing two carats of alloying metal in the pound; and in dealing with any particular alloy of gold and copper would in no way regard its per-centage composition, but would consider it as being so much "better" or "worse" than the one definite and legal standard, according as it contained more or less of the precious metal. The French 20 -franc piece, which contains 90 per cent. of gold, would thus be described as "worse o carats $1_{8}^{5}$ carat grains," and an Austrian ducat, which contains $98.6 \mathrm{I}$ per cent. of gold, as "better I carat $2 \frac{5}{8}$ carat grains." The cumbersome nature of this system is evident; it has the disadvantage of beirg unintelligible to those who employ the decimal system, and who are therefore in the habit of mentally referring to pure gold as Iooo. It is even found wanting in clearness by many who are conversant with the ordinary operations of coinage and bullion transactions generally. For instance, the meaning of "worse $0 \mathrm{I} \frac{5}{8}+\mathrm{I}$ " as the assay report of an ingot is at least obscure, while the equivalent statement that the standard fineness of the ingot is 900 at once suggests that IO0O parts of the metal contain 900 parts of gold.

The ancient system of reporting the results of assays possesses however many points of interest, and Prof. Roberts adds a few details respecting it, taken from a work by Snelling, ${ }^{2}$ an authority on the computation of the value of bullion, who, writing in 1766 , observes that "by the word SILVER we understand not only the metal socalled, pure and unmixed, but also when in a mass with copper ; and if but one-half, two-thirds, or any other proportional part of it be silver, yet the whole bears that name. The same is to be understood of GOLD, when by itself, or in a mass with silver and copper together, or with either of them alone."

"This is the reason that inquiries are not made, what quantity of fine gold or fine silver is contained in any mixture, which seems to be the most natural inquiry, but how much standard it holds." Thus it is that "the Assay Master, in reporting the result of an assay, does not give the absolute fineness or the quantity of fine silver or fine gold present, but only the relative quantity or fineness, that is, how much the mixture is more or less than standard. In the case of gold of 20 carats fine (or 20 parts of pure gold in 24 parts of the alloy) the assayer puts down Wo. $\underset{\mathbf{i j}+,}{\text { car. }}$ and if it is 23 carais $3 \frac{1}{2}$ grains fine,

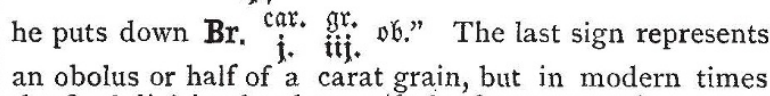
the final division has been $\mathrm{I} / 6$ oth of a carat grain.

It may be pointed out in defence of this complicated system, that, as Snelling proceeds to remark, "the quan-

I "On the Abolition of the Troy Pound," the third Report of the Commissioners appointed to inquire into the condition of the Exchequer Standards. Parliamentary paper [c. 30], 1870 .

2 "Doctrine of Gold and Silver Computations," by Thomas Snelling. (London, r 756 . 
tity of "betterness" or "worseness" in an ingot being added to or subtracted from the weight of it, gives the quantity of standard metal containes in it," and that therefore the "betterness" or "worseness" affords a ready means of determining the amount of copper or gold required to standardise the whole. Further, if a number of ingots of varying weights and fineness have to be dealt with, a similar result will be arrived at by taking the algebraical sum of the several products of their weights and "betterness" or "worseness." These advantages, however, apply to individual calculations, and become unimportant when standarding tables adapted to the decimal system are available. ${ }^{1}$

In a letter to Mr. Fremantle, Prof. Roberts advocated the abolition of this old system of carats and grains and the adoption of the decimal system. This has accordingly been carried into effect. Gold of the value of two millions sterling has recently been imported for coinage, and the simplicity and accuracy of the new system has been abundantly demonstrated.

The facts above stated may seem comparatively unimportant in themselves, but the Mint may at any time be called upon to coin (as was the case in 1872) fifteen millions sterling of gold in a single year, and extreme care has to be taken to insure accuracy in the standard fineness of the metal. It is curious that the old system described above should not have given place before now to that which has long been adopted in other countries.

\section{THE POISONOUS LIZARD"}

THE Gila Lizard of Arizona and Sonora has anterior, deciduous, grooved teeth, which communicate by ducts with large glands within the angle of th. Jwer jaw -an apparatus so strongly resembling the poison-fangs of serpents as to suggest that this lizard has venomous properties. It is said by the natives of Mexico to be very poisonous, but others again have declared that it is perfectly harmless. One specimen sent to Sir John Lubbock killed a frog in a few minutes and a guinea-pig in three minutes.

The conflicting statements are probably due to the fact that the teeth are very small and easily removed. Some specimens of the creature reach the length of three feet. As experiments made by allowing the lizard to bite animals are untrustworthy on account of the uncertainty of getting the poison equally introduced into the tissues at every bite, Doctors Weir Mitchell and Reichert collected the saliva so as to be able to inject it in known quantities. The saliva was obtained by making the animal bite on a saucer-edge. It dropped in small quantities from the lower jaw, and had a faint and not unplensant aromatic odour. It was distinctly alkaline, in contrast to serpent venoms, which are all alike acid. Four and a half minims of it diluted with half a cubic centimetre of water and injected into the breast of a large pigeon caused the bird to walk unsteadily after three minutes. At the same time the respiration became rapid and short, and at the fifth minute feeble. At the sixth minute the bird fell in convulsions with dilated pupils, and was dead before the end of the seventh minute. There was not the least trace of any local effect of the poison, as there would have been in the case of crotalus venom. The muscles and nerves were perfectly sensitive to stimulation mechanically or by weak induced currents. The heart was arrested in complete diastole, and was full of firm, black clots. The intestines looked congested. In another experiment it was found that the poison gradually

I Tables on the system above described were first published in the year 1651, having been prepared by Mr. Reyn lds, Assay Master at the Mint in the Tower A second edition was afterwards issued with corrections and additions in $\mathrm{r} 677$.

2 "A Partial" Study of the Poison of Heloderma suspectum (Cope), the Gila Monster." By Dr. S. Weir Mitchell and Dr. E. T. Reichert of
Philadelphia. lowered the arterial tension and rendered the pulse irregular. Its action on the pulse is not due to any effect upon the pneumogastric nerves, as it is just the same when these nerves are cut. When applied to the heart of a frog it arrests its pulsation; in diastole, and the organ afterwards contracts slowly-possibly in rapid rigor mortis. The cardiac muscle loses its irritability to stimuli at the time it ceases to beat. The other muscles and nerves respond reatily to irritants, but the spinal cord has its power annihilated abruptly and refuses to respond to the most powerful electrical currents.

The authors conclude that "this interesting and virulent heart poison contrasts strongly with the venoms of serpents, since they give rise to local hemorrhages, and cause death chiefly through failure of the respiration and not by the heart, unless given in overwhelming doses. They lower muscle and nerve reactions, especially those of the respiratory apparatu;, but do not as a rule cause extreme and abrupt loss of spinal power. Finally, they give rise to a wide range of secondary pathological appearances which are absent from Heloderma poisoning."

This distinction between the action of the poison of Heloderma and serpent venom is correct as far as regards the poison of the rattlesnake and perhaps also the Crotalidæe generally, but the distinction is by no means marked between the poison of Heloderma and the venom of the cobra. This venom was found by Sir Joseph Fayrer and Dr. Lauder Brunton to have but a slight local action as contrasted with that of the rattlesnake or of the daboia, and to produce no local hernorrbage. The effect of cobra poison on birds also is very much the same as that of the Heloderma; and in the experiments given in this preliminary paper, the effect of the Heloderma poison on the heart of the frog is very much like that of cobra poison, the failure of action with subsequent and gradually increasing contraction being almost precisely the same. ${ }^{1}$

In Brunton and Fayrer's experiments on cobra poison, the fall of blood-pressure was less marked, but it still occurred. Paralysis of the spinal cord also is produced by cobra poison, and the experiments in this preliminary paper are too few to enable us to decide whether the paralysing effect is greater from the poison of Heloderma than from cobra venom. We shall look with much interest to the further study of the venom of this curious animal, which the authors intend to make on the arrival of the fresh specimens which they are about to receive.

\section{ON THE CONDENSATION OF VAPOUR FROM THE FUMAROLES OF. THE SOLFATARA OF POZZUOLI}

THE fumaroles of the Solfatara of Pozzuoli, and especially the larger fumarole known as the Bocia della Solfatara, give a striking illustration of the action of smoke in causing the condensation of aqueous vapour in the manner demonstrated by the experiments of Coulier, and more especially by those of Dr. Aitken.

Persons who have visited the Solfatara will remember that one of the feats by which the ciceroni of the place try to excite the wonderment of visitors is to light some paper or a few dry branches, and put the flaming body before or inside the mouth of the principal fumarole, augmenting thus very greatly the volumes of cloudy vapour escaping from the fissure. This phenomenon can be observed in all volcanic fumaroles. A flame is not indispensable, the condensation of the vapour being also produced by the mere smouldering of tinder.

Prof. Piria first tried to explain the phenomenon. $\mathrm{He}$ thought that small quantities of sulphuretted hydrogen issued from the soil together with the aqueous vapour:

$x$ Brunton and Fayrer on the Poison of Indian Venomous Snakes (Roy. Soc. Proceedings, January 22, 18/4, p. I26). 